\title{
Evaluation of Flexible Pavement Deflections with Respect to Pavement Depths Using Software (A Case Study Jimma to Seka Road)
}

\author{
Tarekegn Kumela \\ Faculty of Civil and Environmental Engineering, Jimma University, Institute of Technology, Jimma, Ethiopia
}

\section{Email address:}

tarekum2006@gmail.com

\section{To cite this article:}

Tarekegn Kumela. Evaluation of Flexible Pavement Deflections with Respect to Pavement Depths Using Software (A Case Study Jimma to Seka Road). American Journal of Civil Engineering. Vol. 6, No. 5, 2018, pp. 141-146. doi: 10.11648/j.ajce.20180605.11

Received: September 22, 2018; Accepted: October 24, 2018; Published: November 15, 2018

\begin{abstract}
Road building in Ethiopia is increasingly in demand to meet medium and long terms development programs. Roads are constructed radiating from the capital city of the country in all direction. The objective of this research study is to evaluate the flexible pavement deflections with respect to pavement depth using Software along Jimma to Seka road segment and compare the laboratory results with the Ethiopian Road Authority (ERA) standards. Ever Stress Software (ESS) is a numerical analysis technique to obtain the deflection of pavement layers. The methodology of this research was finding the sensitivity of the road parameters (dimension, layers thickness, elastic modulus, Poisson's ratio, loads and pressures) in reducing the major causes of failure in asphalt pavement fatigue cracking and rutting due to vertical surface deflections, the critical tensile strains at the bottom of the asphalt layer and the critical compressive strains on the top of subgrade. The analytical method used was the elastic modulus and Poisson's ratio of the pavement materials as design parameters after CBR results of each layers was obtained. The expected outputs have shown that the displacement or deflection $\left(\mathrm{u}_{\mathrm{z}}\right)$ was as high as $0.38 \mathrm{~mm}$ in the asphalt surface and gradually decreased as the pavement thickness increased. Large values of deflections indicates an over stressed condition which results in the pavement surface to crack and distortion as a results of fatigue or accumulated plastic deformation. Therefore, the relative deflection of pavement layer decreases as the pavement depth increases.
\end{abstract}

Keywords: Deflections, Flexible Pavement, Layers Thickness, Pavement Modulus

\section{Introduction}

Flexible pavements with asphalt concrete (AC) surface courses are used all around the world. The various layers of the flexible pavement structure have different strength and deformation characteristics which make the layered system difficult to analyze in pavement engineering. Asphalt concrete in the surface layer is a viscous material with its behavior depending on time and temperature.

Most of the currently used flexible pavement structural analysis models assume linear elastic behavior. As the demand for applied wheel loads and number of load applications increases, it becomes very important to properly characterize the behavior of unbound granular material and subgrade soil layers as the foundations of the layered pavement structure.

The major causes of failure in asphalt pavement are fatigue cracking caused by excessive vertical compressive and horizontal tensile strain at the top subgrade and bottom of asphalt layer due to repeated traffic loading and rutting deformation, caused by densification and shear deformation of sub grade. Excess vertical surface deflections in flexible pavements have always been major concern and used as a criterion of pavement design [1].

This research studies the analysis of the deflection of flexible pavements using ever stress software. It is a numerical analysis technique to obtain the deflection of pavement layers. Analytical method usually uses elastic modulus and Poisson's ratio of the pavement materials as design parameters. These variables can use to improve pavement performance. It is expecting that this study can use as a guideline to assist design engineer to select the appropriate pavement structure [2].

The aim of this paper is to study the sensitivity of the road 
parameters (dimension, layers thickness, elastic modulus, Poisson's ratio, loads and pressures). Because, in reducing the vertical surface deflections, the critical tensile strains at the bottom of the asphalt layer and the critical compressive strains on the top of subgrade using the finite element method by relating the standard specification of road condition from the existing documented data. These variables can use to improve pavement performance. It is expected that this study can use as a guideline to assist design engineer to select the appropriate pavement structure [3].

\section{Statement of the Problems}

In the analysis of flexible pavement, axle loads on the surface of the pavement produce two different types of strains, which are believed to be most critical for design purposes. These are the horizontal tensile strains at the bottom of the asphalt layer, and the vertical compressive strain at the top of the subgrade layer. If the horizontal tensile strain is excessive, cracking of the surface layer will occur and the pavement will fail due to fatigue. If the vertical compressive strain is excessive, permanent deformations are observed at the surface of the pavement structure (from overloading the subgrade) and pavement fails due to rutting [4]. The use of Ever stress allows the model to accommodate the load dependent stiffness of the road layers, granular and subgrade materials. Although most of the models still use linear elastic theory as constitutive relationship. The load come from vehicles must be distributed properly otherwise it-enforced deflection of the road.

\section{Objectives}

The general objective of this study was the structural analysis of flexible pavements deflection using sensitivity of the road parameters using ever stress software along Jimma to Seka road section.

Specific objectives

(1) To identify the parameters that are related to the deflection of flexible pavement that corresponding to CBR numerical values using laboratory test.

(2) To evaluate the deflection of flexible pavement materials by using software.

(3) To recommend remedies in reducing vertical surface deflections of the asphalt layers with comparison ERA standard.

\section{Methodology}

\subsection{Description of Study Area}

The study to be carried out within Jimma to Seka road found in the South-Western part of Ethiopia. It is located 360 to 375 kilometers South-west of the capital Addis Ababa. The total length of the road is about $15 \mathrm{~km}$ asphalt pavement. Jimma-Seka road is at the center of the road network for South-west of Ethiopia.

The first major road dates to the early 1940s, with a road that extended from the capital Addis Ababa to Seka as a strategy for fostering economic growth in Ethiopia through generation of transportation to connect South-western part to Addis Ababa. The existing Jimma to Seka road comprised of $15 \mathrm{Km}$ of $50 \mathrm{~mm}$ thick asphalted pavement with Double Bitumen Surface Treatment (DBST) shoulders. It connects the mainly coffee growing areas in the region with the Capital City of Addis Ababa through Jimma-Addis main route.

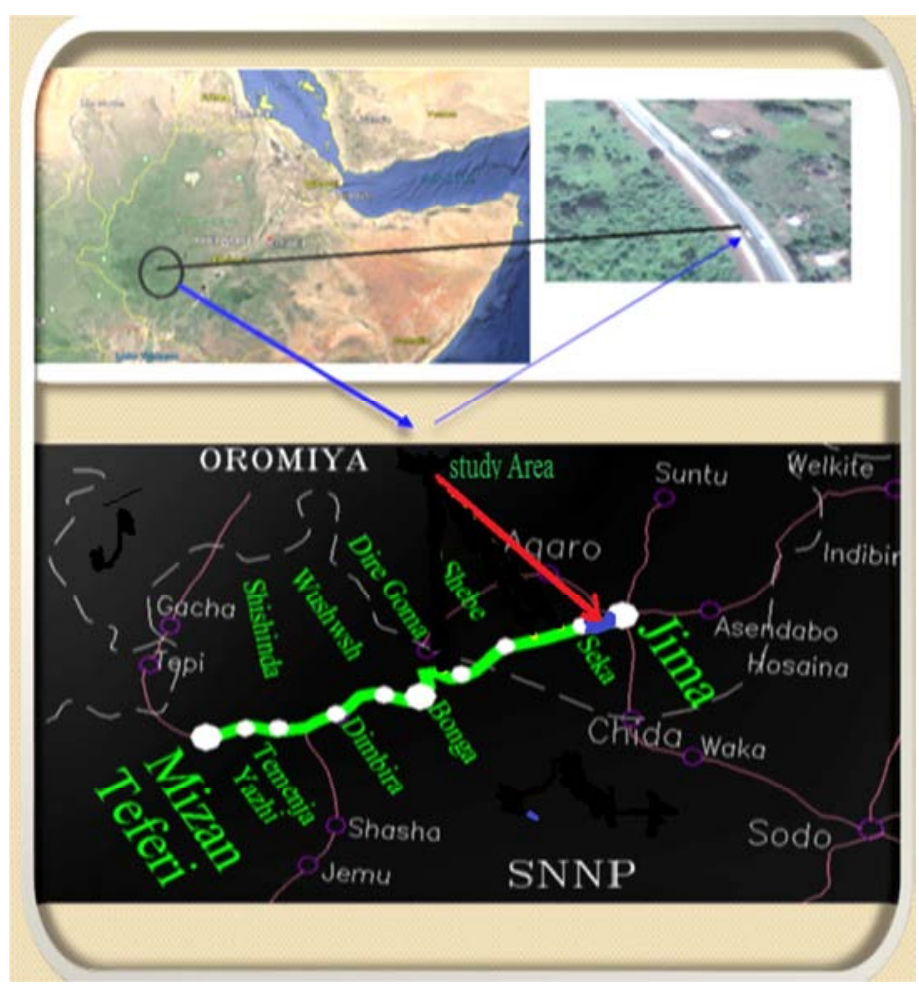

Figure 1. Map of study area.

The geographical location of the study area is characterized by the following degree of latitudes and longitudes. Latitudes of 07040 '07.3" and 060 59'44.3" in the North-South direction and Longitudes of $36049^{\prime} 43.6$ " and 35035 ' 17.9" in the South-West direction.

The soils of the Study area are predominantly Dystric nitisols. These are reddish brown to dark reddish brown soils, with clay to clay loam texture, $\mathrm{pH}<5.5$ and have relatively low fertility status. Orthic acrisols are also found, mainly on the steep valley slopes, and have broadly similar properties. The soils are predominantly well drained [5].

\subsection{Design of the Study}

For this study, analytical, applied, descriptive, quantitative, and qualitative types of research, approach was adopted directly or indirectly. It is quantitative and qualitative approach because the conclusion of the findings depends on the manipulation of those data. It is similarly analytical, applied and descriptive because it systematically identifies numerical analysis and addresses the practical cause, problem, and their solution. It describes the input data, process, output and the methodology. The methodology of this work has the following components. 


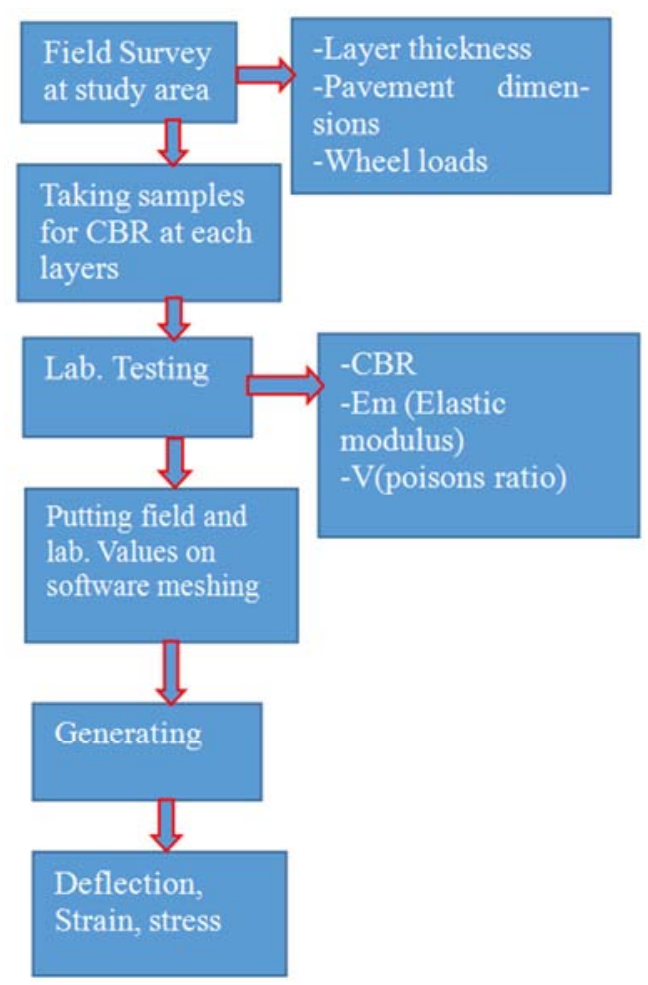

Figure 2. The analysis methods of Input, Process, and results.

\subsection{Field Observation and Laboratory Test}

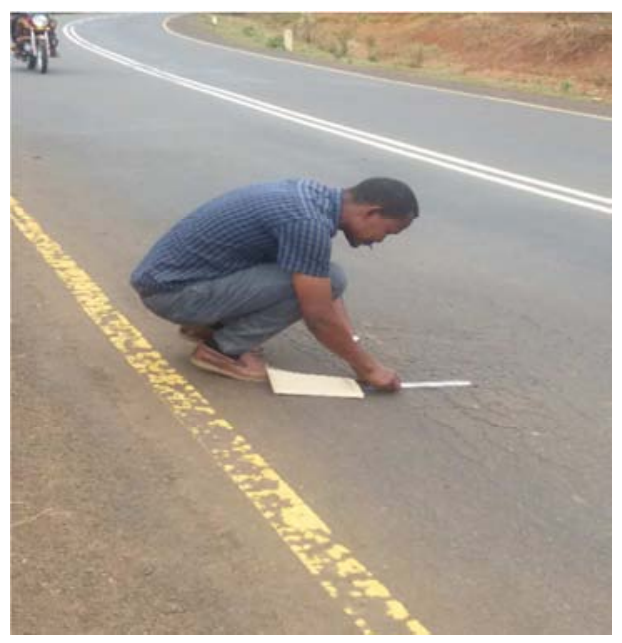

Figure 3. Field observation along study area.

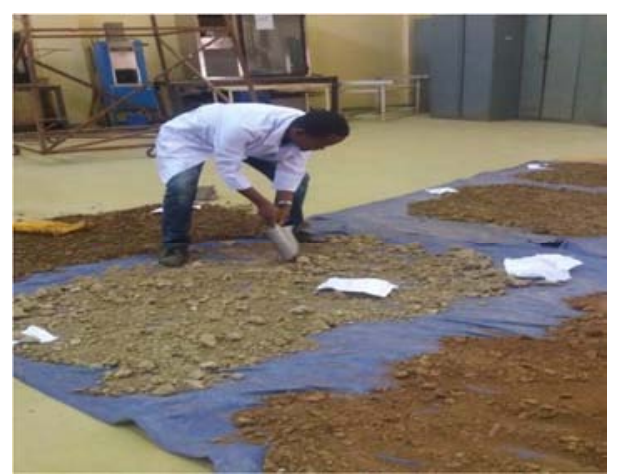

Figure 4. Sample preparation for CBR test.
Most type of distress along Jimma -Seka road is rutting deflection. The most cause of rutting deflection along Jimma -Seka is expected to overloading in case of coffee and timber materials transport.

\subsection{California Bearing Ratio Test (CBR-Test)}

The California bearing is a comparative measure of the shearing resistance of a soil, which is restricted to pavement. It gives a precaution to allow for moisture content increase in the soil due to flooding or elevation of water table. The CBR value for a soil will depend upon its density, molding moisture and moisture content after soaking. It is done to provide the relative bearing values of each layers and swellness.

The objective was to determine strength of soil, subgrade, sub base and base course materials in terms of CBR and to know the bearing capacity of each layer. The strength of a sub grade, sub base and base course materials are expressed in terms of their CBR value. To observe the effect of rain on soil and percent of swell and to know the bulk and dry density.

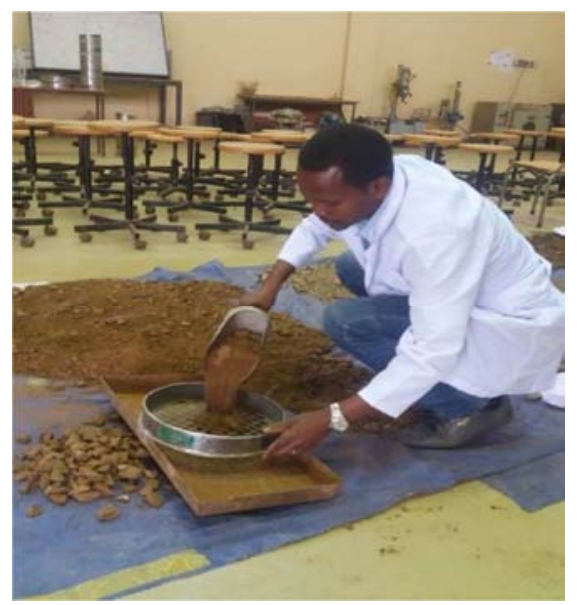

Figure 5. Sample preparation for CBR test.

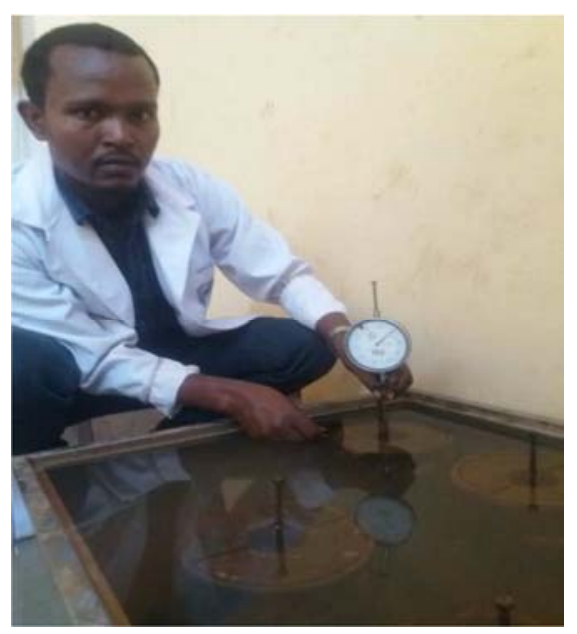

Figure 6. Measuring soaked CBR with its machine.

The CBR is compressive measure of the shearing resistance of a soil. It is done for to provide the relative bearing values of each layers and swellness. While this test is proceed there are 
different check to bed one, penetration, soaking condition, swell test.

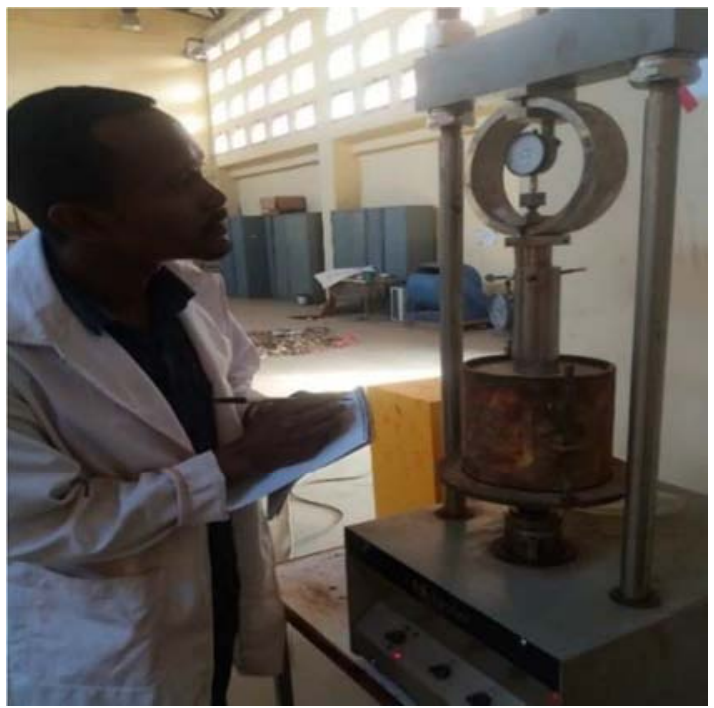

Figure 7. Taking soaked CBR values.

Figure 7. Shows that the soaked California Bearing Ratio (CBR) test requires the dynamically compacted sample to be immersed in water for 96 hours or for 4 days. So that it attains the optimum moisture content to perform the penetration test. After the sample was being soaked for 4 days the penetration piston us being set at the center of the specimen with the smallest possible load.

\subsection{Component of Road Layers}

Jimma -Seka asphalt concrete consist the following component of layers, which is different thickness. The thickness of each layers are the same throughout Jimma -Seka road. The components are surface course, base course, sub base course, and subgrade course. (Source: Jimma -Seka road upgrade documentary).

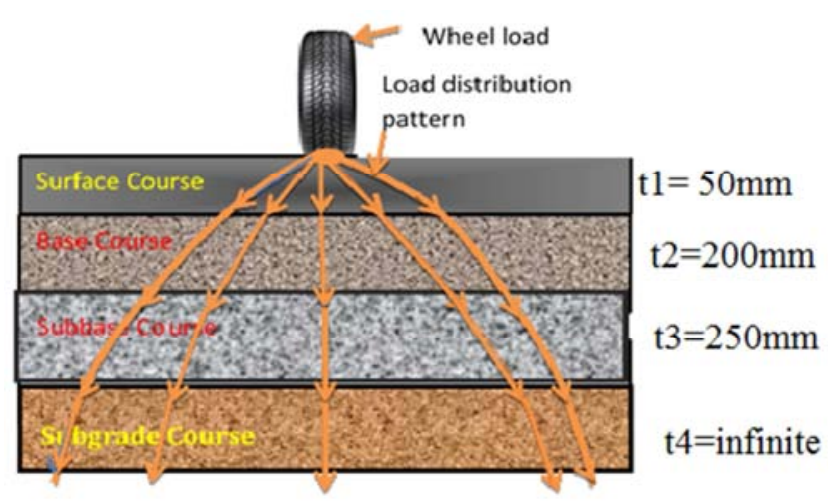

Figure 8. Basic thickness of road at study area.

\section{Result and Discussion}

The main cause of vertical surface deflections and the horizontal tensile strains in layers of flexible pavements were vertical loads. The detrimental effects of axle load and tire pressure on various pavement sections are investigated by computing the tensile strain $\left(\varepsilon_{\mathrm{t}}\right)$ at the bottom of the asphalt layer and the compressive strain $(\mathcal{E} c)$ at the top of the subgrade. Then, damage analysis is performed using the two critical strains to compute pavement life for fatigue cracking and permanent deformation (rutting). Sensitivity Analyses demonstrate the effect of various parameters on flexible pavement. Materials in each layer are characterized by a modulus of elasticity $\left(\mathrm{E}_{\mathrm{m}}\right)$ and a Poisson's ratio (v). Poisson's ratio; $v$ is considered as $0.35,0.30,0.30$ and 0.30 for asphalt layer, base course, sub-base course and subgrade course, respectively. Traffic is expressed in terms of repetitions of single axle load $40 \mathrm{KN}$ applied to the pavement on two sets of dual tires. The investigated contact pressure was $690 \mathrm{KPa}$. The dual tire is approximated by two circular plates with radius $135 \mathrm{~mm}$ and spaced at $350 \mathrm{~mm}$ center to center. The following table show Jimma - Seka road pavement materials properties from laboratory test result and the specification result.

Table 1. Laboratory results of Pavement material properties with ERA standards.

\begin{tabular}{|c|c|c|c|c|c|c|c|}
\hline \multirow{2}{*}{ Road properties } & \multirow{2}{*}{ Layers thickness (mm) } & \multicolumn{3}{|c|}{ Laboratory Test Results } & \multicolumn{3}{|c|}{ ERA Standard Specification Results } \\
\hline & & CBR \% & $\mathbf{E}_{\mathrm{m}} \cdot \mathbf{M P a}$ & v & CBR \% & $\mathbf{E}_{\mathrm{m} \cdot \mathrm{MPa}}$ & v \\
\hline Asphalt concrete & 50 & - & 3000 & 0.350 & - & 3000 & 0.35 \\
\hline Base course & 200 & 83.2 & 325 & 0.30 & $>80$ & 300 & 0.30 \\
\hline Subgrade course & - & 7.78 & 91.05 & 0.30 & $>15$ & 100 & 0.30 \\
\hline
\end{tabular}

The thickness of the flexible asphalt concrete (AC) layer, base and sub base course layers were taken as $50 \mathrm{~mm}, 200 \mathrm{~mm}$ and $250 \mathrm{~mm}$, respectively. The subgrade layer was considered to be infinitely thick. However, a portion of the subgrade was also modeled with finite elements. The thickness of the flexible asphalt concrete (AC) layer, base and sub base course layers were taken as $50 \mathrm{~mm}, 200 \mathrm{~mm}$ and $250 \mathrm{~mm}$, respectively. The subgrade layer was considered to be infinitely thick. However, a portion of the subgrade was also modeled with finite elements.

The horizontal and vertical strains are considered to be the most critical in the road structure for permanent deformation to develop. The result of strain along $\mathrm{x}$-axis $(\mathcal{E x x})$ and $\mathrm{y}$-axis (Eyy) as shown in the above figure 9 the horizontal tensile strain or positive values at the bottom of the sub grade soil.

Sub grade indicates that it has the risk of pavement fatigue cracks at the top of the asphalt. In addition to this pothole, longitudinal and alligator crack could also occur. While the vertical or compressive strain or negative values in $\mathrm{z}$-axis $(\mathcal{E z})$ at top of the sub grade indicates that it has the risk of pavement permanent rutting deflection at the top of the asphalt.

Figure 10 shows that the effects of flexible pavement under the center of wheel load applied on it. The amount of pavement deflection under the load indicates, in part its 
adequacy in so far as its structural capacity is concerned. The applied loads bring more stressed especially in the base course and base layers of the pavement than the rest layers.

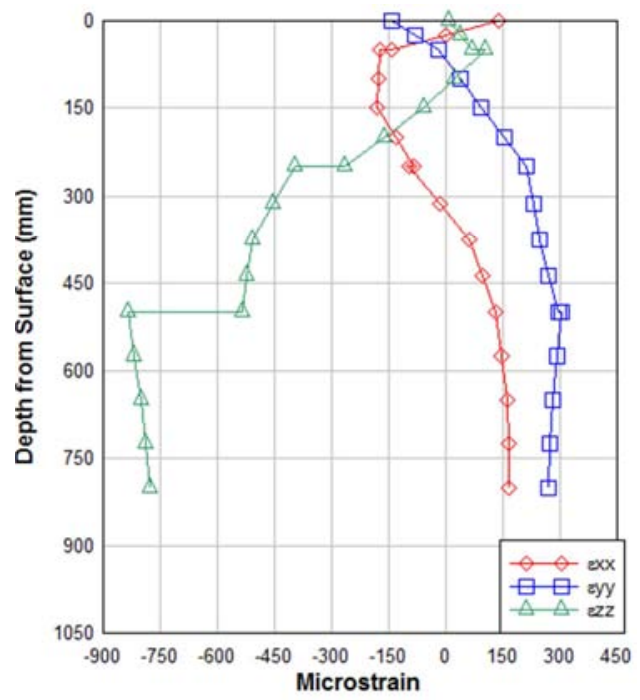

Figure 9. Normal strain versus pavement depth.

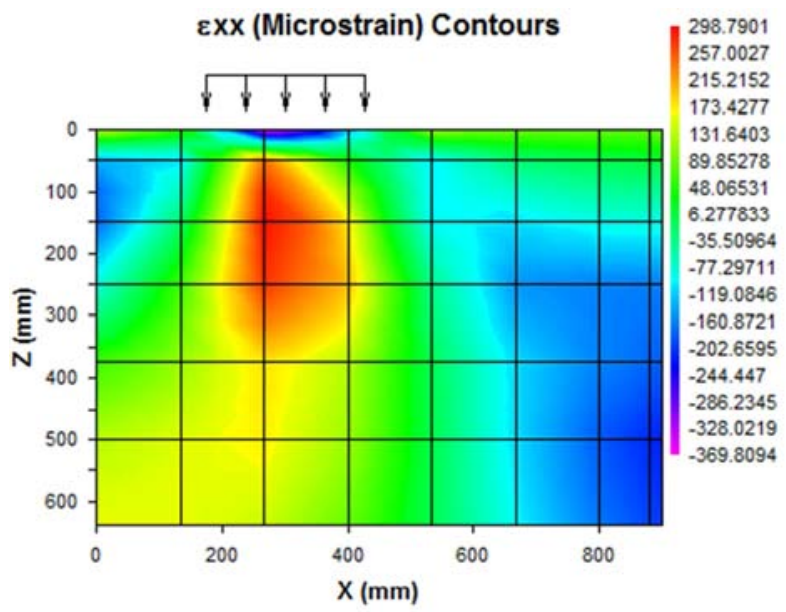

Figure 10. Vertical depth versus horizontal length of strain.

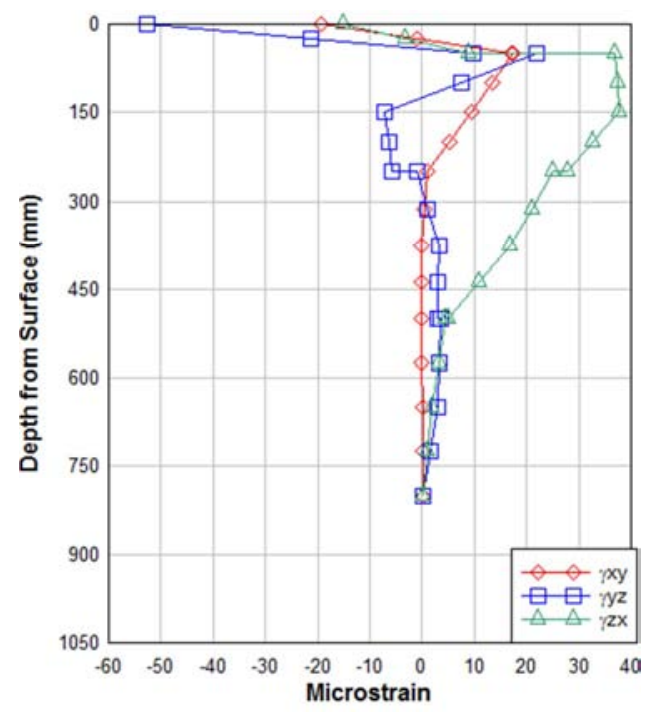

Figure 11. Shear strain versus depth.

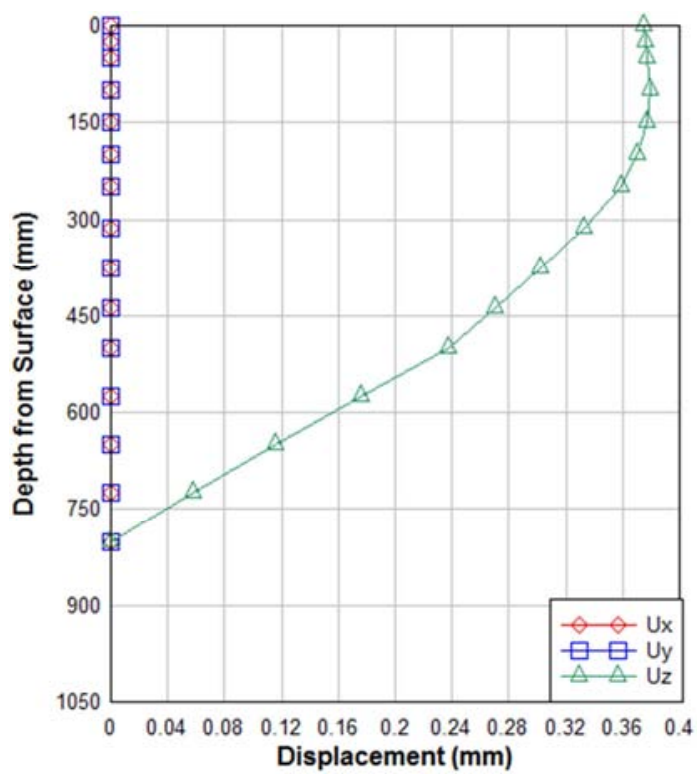

Figure 12. Displacement (deflection) versus depth.

From figure 11, the shear strains became negative values in the asphalt layer but, they became positive values in base course and sub base layers and eventually they came to neutral or zero. In figure 12 the displacement or deflection $\left(\mathrm{u}_{\mathrm{z}}\right)$ was high in the asphalt surface and gradually decreased as the pavement thickness increased. Large deflections indicates an over stressed condition which causes the pavement surface to crack and distortion as a results of fatigue or accumulated plastic deformation. Therefore, figure 12 satisfies the relative deflection of pavement layer decreases as the pavement depth increases. To make use of component deflections it is necessary to take account decreased stress with increased depth.

\section{Conclusions}

The primary purpose of determining the deflection is to check the structural adequacy of the existing pavement as along the study area. Therefore:

a) The parameters that are related to the deflection of flexible pavement are shear stresses and strains in addition to consolidation of one or more of pavement component. The performance of the flexible pavement was influenced by many factors. These includes gross load, CBR values, and tire pressure, repetition of loads, pavement thickness and durability of various pavement components particularly the sub grade soil properties.

b) The amount of deflection of the flexible at the study area was $0.38 \mathrm{~mm}$ which is less than the optimum deflection amount 0.02 inch or $0.5 \mathrm{~mm}$.

c) The relative deflection of the pavement layer decreases as the depth increases as shown in figure 12. Therefore, to make use of component of deflections and it is necessary to take in to account decreased stress with increased depth. 


\section{Recommendation}

1) It was recommended that there should be detail research conducting in which pavement stresses and strains are measured simultaneously under controlled loading conditions in order to check theoretical hypothesis regarding the elastic and viscoelastic behavior of pavements.

2) Effects of vehicles speed, temperature of the area, weather and climate of the study area should be farther investigated.

\section{Acknowledgements}

I would like to thank the almighty God. My deepest gratitude goes to my families specially my wife Ms. Asanti Keno who have initiated me with the knowledge in all procedure and guidance of this research work; my great appreciation for their guidance, wisdom, and patience in order to finish this research work.

My gratitude also goes to the JiT laboratory technicians for their supporting all the times during the laboratory activities and the Jimma University for supporting money.

Special thanks go to all my past and present staff members for their friendship and support.

Finally, my appreciation and thanks goes to all my family, friends and relatives who have helped me in any form of support which are greatly needed for the advancement and completion of this work.

\section{References}

[1] Gupta. (2014). comparative structural analysis of flexible pavements using finite element method. The International Journal of Pavement Engineering and Asphalt Technology, Volume: 15, pp. 11-19.

[2] Taneerananon, Somchainuek, Thongchim, \& Yandell. (2014). analysis of stress, strain and deflection of pavements using finite element. Journal of Society for Transportation and Traffic Studies, Vol. 1 No. 4.

[3] Taneerananon, Somchainuek, Thongchim, \& Yandell. (2014). analysis of stress, strain and deflection of pavements using finite element. Journal of Society for Transportation and Traffic Studies, Vol. 1 No. 4.
[4] Garba, R. (2002). A Thesis on Permanent Deformation properties of Asphalt Concrete mixtures. Department of Road and Railway Engineering, Norwegian University of Science and Technology.

[5] Ethiopian Roads Authority Standard Manuals. Jimma-Mizan Road upgrading project. 2007.

[6] Burmister, D. (1945). The general theory of stresses and displacements in layered soil system. Journal of applied physics, vol. 16, pp. 84-94, 126-126-127, 296-302.

[7] Emmanuel O., E. a. (2009). Fatigue and rutting strain analysis of flexible pavements designed using CBR methods. African Journal of Environmental Science and Technology, Vol. 3 (1 2), pp. $412-421$.

[8] Yang, H. (1973). Asphalt Pavement Design - The Shell Method, Proceedings. 4th International Conference on Structural Design of Asphalt Pavements.

[9] Zaghloul S and White, T. (1993). Use of a Three Dimensional, Dynamic Finite Element Program for Analysis of Flexible Pavement. In Transportation Research Record 1388, TRB, Washington D. C., pp. 6069.

[10] Emmanuel O., E. a. (2009). Fatigue and rutting strain analysis of flexible pavements designed using CBR methods. African Journal of Environmental Science and Technology, Vol. 3 (1 2), pp. $412-421$.

[11] Choudhary, D. K.; Joshi, Y. P. 2014. A Detailed Study of Cbr Method for Flexible Pavement Design, International Journal of Engineering Research and Applications, 4 (6), pp. 239-253.

[12] Cai, Y.; Sangghaleh, A.; Pan, E. 2015. Effect of anisotropic base/interlayer on the mechanistic responses of layered pavements, Computers and Geotechnics, 65, pp. 250-257.

[13] Androjić, I., Dimter, S. 2015. Influence of compaction temperature on the properties of Marshall Specimens. // The Baltic Journal of Road and Bridge Engineering. X (2015), 4, pp. 309-315.

[14] Gupta, A., Kumar, P., and Rastogi, R. (2014), "Critical Review of Flexible Pavement Performance Models", Korean Society of Civil Engineers (KSCE), Journal of Civil Engineering, Springer, Vol. 18, No. 1, pp. 142-148.

[15] Abed, A. H., and Al-Azzawi, A. A. (2012), "Evaluation of Rutting Depth in Flexible Pavements by Using Finite Element Analysis and Local Empirical Model", American Journal of Engineering and Applied Sciences, Vol. 5, No. 2, pp. 163-169. 